\title{
STRATEGISING MINERALS: SECURING SUSTAINABLE SUPPLY
}

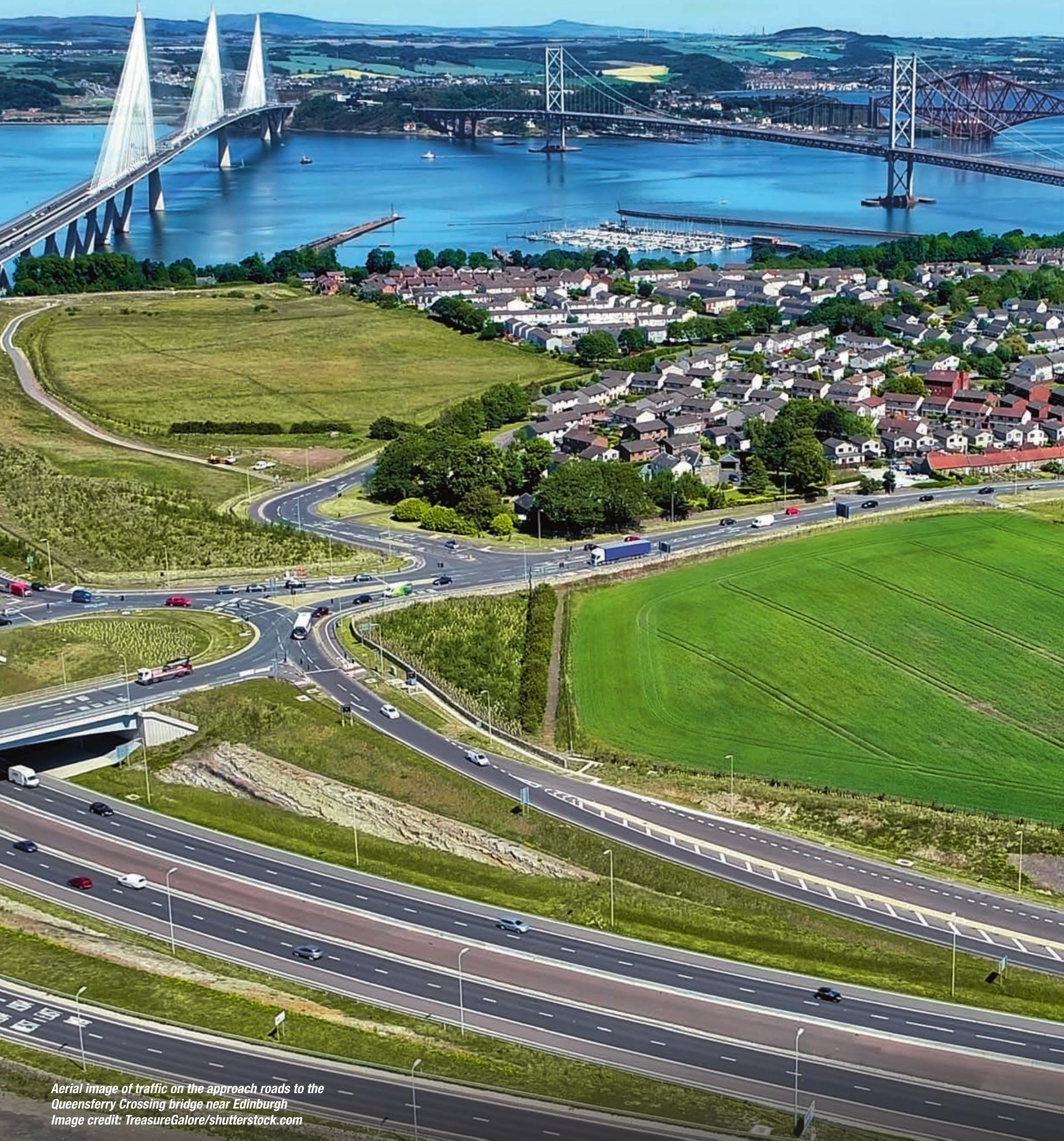




sector. Nigel Jackson* lauds the UK Minerals
Strategy for raising awareness

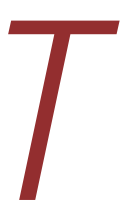

here is widespread ignorance generally, and more worryingly within Government, of the importance and economic contribution of the UK minerals industries. That is, non-energy related minerals and mineral products, such as aggregates, concrete, asphalt, agricultural and industrial lime, potash, clays and sands-raw materials that are essential to build infrastructure, fertilise our soils, and sustain construction and the economy.

To combat this ignorance, the UK Minerals Strategy (UKMS) has just been launched. This industry-led response is designed to raise awareness of the minerals industry, its contribution to the economy and our way of life, among central and local Government, key stakeholders and the general public. The strategy also aims to bring the industry together, to shape a common approach and ensure sustainable supplies for the next 25 years.

\section{A mining nation}

The entire UK economy relies on minerals (Fig. 1). They are critical to develop and maintain our built environment and sustain our quality of life. Most people do not think about where the materials for construction and manufacturing come from and many assume that, with the decline of coal, we are no longer a mining nation. Not so. The UK has diverse geology—on land and offshore-meaning that the vast majority of the demand can be met from indigenous sources. We remain very active, with over 2,000 extraction, processing and production sites onshore and offshore using ports, wharves, rivers, canals and the rail network (Figs. 2 and 3). Activity spans construction and industrial minerals, with recent tungsten and planned polyhalite operations in Devon and Cleveland, respectively, and active interest in tin, gold and lithium all testifying to the potential that remains. But mineral supply cannot be assumed: it needs planning, monitoring and managing. Planning authorities lack the resources to undertake meaningful assessments, so there are no up-to-date estimates of future requirements, risking under provision. The current mineral planning system enables planning applications for new mineral sites to be converted into production via a 'predictand-provide' approach based on local plans. Whether this is a robust and appropriate basis on which to meet demand for the biggest material flow in the economy going forward is an open question.

Based on recent consumption, the industry estimates that more than five billion tonnes of minerals and mineral products will be needed over the next 25 years. Current replenishment rates, particularly for aggregates that represent over $80 \%$ of our mineral needs, have been languishing at around or below $60 \%$ for over 10 years. Given that it can take anything from 10 to 15 years to move from exploration to production, alarm bells should be ringing.

\section{Strategic vision}

Support for the minerals industry should be a national priority and policy imperative. Yet, there is no overarching Government strategy. Instead, individual planning documents exist for England (the National Planning Policy Framework, NPPF), as well as for Scotland, Wales and Northern Ireland. There is an emerging Industrial Strategy that aims to boost productivity and create jobs through investment. And this strategy will link with the Construction Sector Deal which aims to cleanly and efficiently build smarter, safer homes and buildings, through a strategic partnership between Government and the industry.

The UKMS was developed in anticipation of this emerging Industrial Strategy, to champion the minerals industry, the essentiality of its products and the need to ensure a steady and adequate supply of minerals to meet societal demand. 
The development of this industry-led strategy has been a unique process that has taken around 25 years.

\section{The trigger}

In 1993, a number of trade associations, geologists, mineral planners, consultants and lawyers formed the then CBI Mineral Committee. Frustrations with the planning and permitting system were raw. The committee concluded that enough was enough; the industry must get its act together if it was to survive and prosper, and to ensure the economy received sustainable supplies of the minerals it needs, at the right level and the right rate.

The committee published 'Living with Minerals' as a first attempt to set out the scale, importance and nature of the industry, and to make the link between minerals and their end use. The document includes a cut away of the minerals and mineral products used in a typical home, which is emblematic of the case being made.

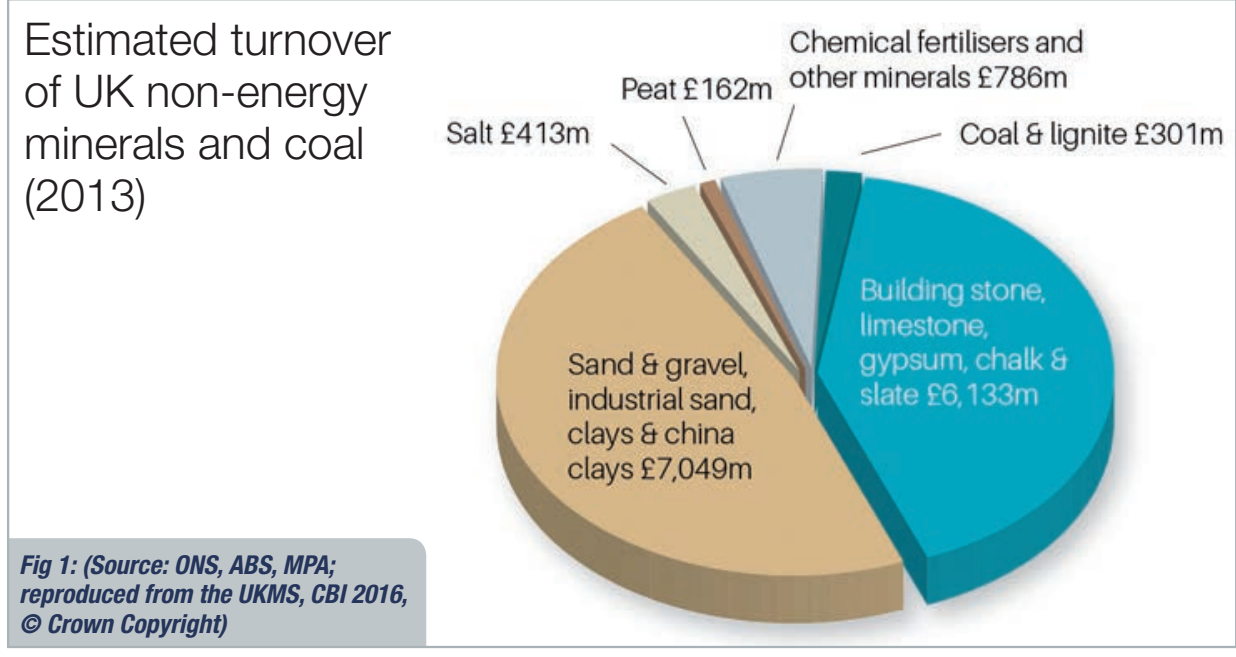

Crown Copyright)
But knowing there is a problem was the easy part. Developing a solution is what has taken the time. The industry needed to organise itself, engage with others using evidence-based dialogue, debate key issues, put its ideas together, consult and conclude.

\section{The response}

The CBI Minerals Group brought together 99.9\% of the industry, in concert with the Mineral Products Association which, representing over $90 \%$ of the UK mineral products industry, has the resources to help deliver solutions.

To engage with key stakeholders, the UK Minerals Forum (UKMF) was formed in 2007. Although funded by the industry, the forum is independently chaired and brings together the planners, NGOs, and representatives from Government and its agencies across the UK to debate important and controversial issues. The forum produced consensus reports and helped build trust between industry and its stakeholders.

In parallel, six 'Living with Minerals' conferences held since 2004 have identified key issues necessary to shape a credible strategy. Together, these forums and conferences led to the publication of three important documents between 2014 and 2016: 1) the House of Commons Select Committee Investigation into the Extractive Industries Sector (Nov 2014), which endorsed the development of a strategy; 2) the UK Minerals Forum report 'The Future of our Minerals' (Nov 2014), which examined recent and future trends in production, and recommended developing a long-term vision for UK mineral supply; and 3) the CBI Minerals Group report 'The UK Minerals Extraction Industry' (Feb 2016), which quantified the economic contribution of the industry.

These outputs motivated the industry to keep moving forward and convert years of preparation into a UK Minerals Strategy.

\section{The Strategy}

The first ever UK Minerals Strategy launched this summer (Fig. 4). The overarching aim is to ensure that UK demand for minerals and mineral products is supplied sustainably for the next 25 years, by identifying and permitting at least five billion tonnes of minerals to be sourced primarily from indigenous sources.

The strategy is multi-layered, from the political to the operational. It aims to raise awareness and make the link between our mineral resources and their end use, thus selling the importance of this industry to 
the next generation. The document serves as a reference and reminder for the industry, Government and planners of the crucial need for these minerals, encouraging them to view planning applications favourably, invest in research, development and exploration to find new indigenous resources, invest in skills to create a new generation of specialists to work in the industry, and, importantly, to do all this safely and sustainably.

The UKMS is constructed around three building blocks of sustainable development (table 1): economic, environment and social. In turn, these are divided into nine blocks, creating the opportunity to build bespoke communities of interest, to ensure manageability and affordability.

Work on the three building blocks will start soon. Mineral extraction is a long-term business, where lead-in times for planning and permitting to production can typically take up to 10 to 15 years. Thus, to meet demand in 25 years' time, the nine key blocks need to be completed in around three years.

The project is ambitious, but, significantly, already has support from the industry's sponsoring Government Minister, Richard Harrington MP. The aim of linking the UKMS to Government's own ambitions for the industry and the economy has been recognised, which is both satisfying and welcomed. The strategy is also attracting support from non-industrial organisations with a legitimate interest in the industry.

UKMS should be viewed as this generation handing the baton to the next, to ensure that this great industry continues to thrive for the good of the economy and our quality of life.
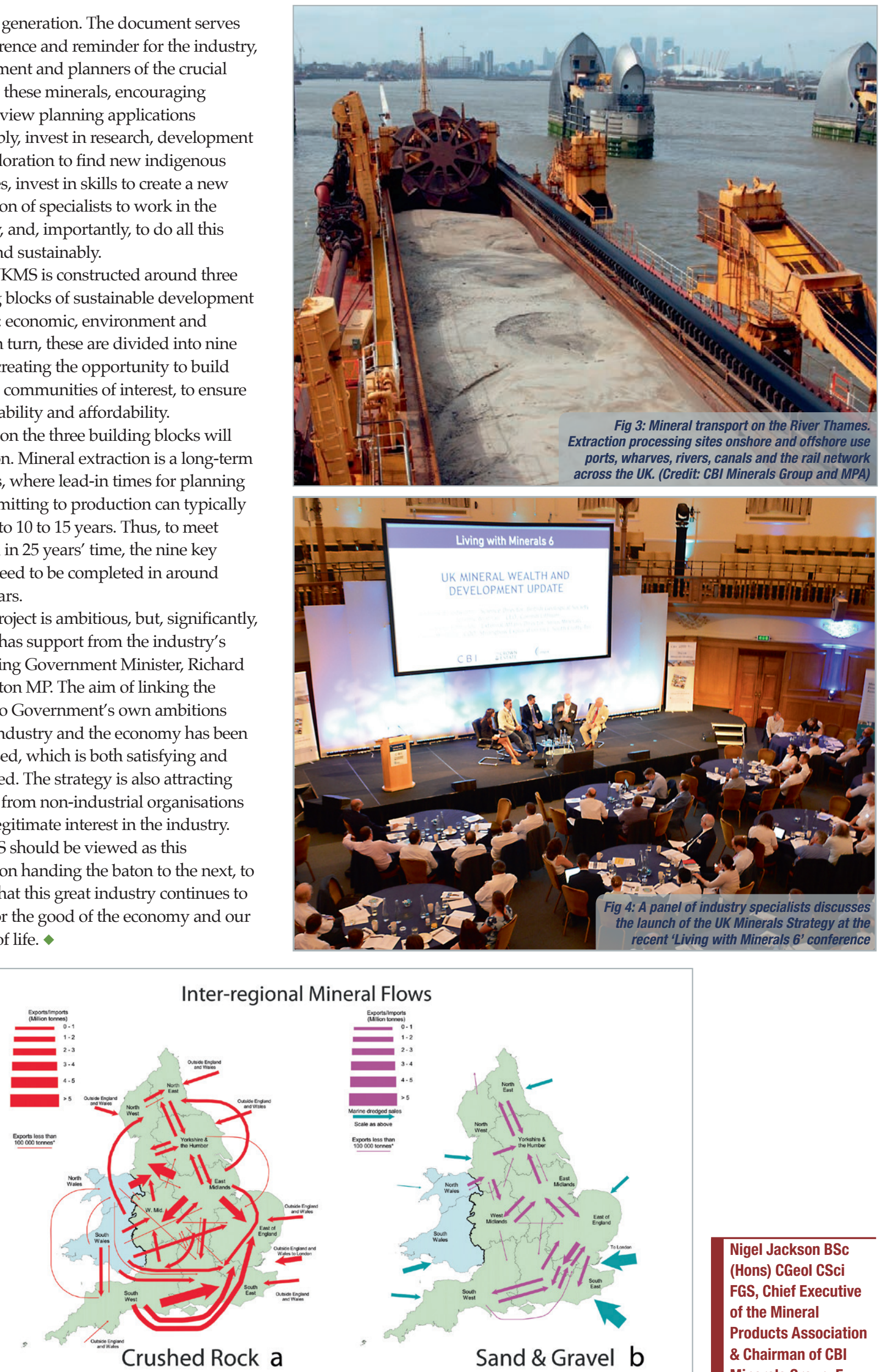